\title{
La política exterior de Venezuela hacia Nicaragua y El Salvador (1974-1984)
}

\section{Ma. del Carmen Collado}

Desde el punto de vista geográfico Venezuela forma parte de la región. caribeña, además de pertenecer a la amazónica y a la andina; de ahí la importancia de su política exterior hacia aquella región. Sin embargo, podría parecer que la diplomacia venezolana se extralimita al tratar de mantener su influencia en una región más alejada, como es América Central, pero la interdependencia entre el Caribe y Centroamérica y el hecho de que ambas forman la cuenca caribeña porque todos sus países tienen costas en el mar Caribe, excepto El Salvador, explican la unidad de la política exterior en ambas regiones y el interés de Venezuela hacia América Central. ${ }^{1}$

Las insurrecciones populares de Nicaragua y El Salvador han llenado las primeras planas de los periódicos de nuestro continente durante los últimos años. Centroamérica se ha convertido en área de graves tensiones mundiales y muchas naciones y líderes internacionales han opinado o tratado de influir en la situación de los países que la componen. En ese sentido es interesante analizar la política exterior venezolana y los giros que se han dado desde el gobierno de Carlos Andrés Pérez hasta el de Luis Herrera Campins. La diplomacia de Venezuela en Centroamérica ha sido, entre 1974 y 1984 , zigzagueante y, al menos aparentemente, contradictoria. Intentaremos explicar las razones de estos cambios en función del interés nacional de Venezuela, de su situación interna, de su papel en el hemisferio, de la propia concepción oficial de las relaciones internacionales y del contexto mundial y regional alrededor de sus relaciones exteriores.

La política exterior venezolana hacia Nicaragua y El Salvador entre 1974 y 1984 se enfocará en dos niveles. El primero, partiendo del análisis del sistema mundial, del hemisférico y del centroamericano, buscando la relación con la política exterior de Venezuela. En el segundo nivel se establecerá la influencia de la política interior sobre la política exterior. Se analizarán las siguientes variables: el ingreso petrolero, los partidos políticos, el personalismo, la Internacional Socialista y la Democracia Cristiana, los intereses de la burguesía nacional y el modelo democrático en la política centroamericana.

\section{La política exterior venezolana en el nivel mundial y el hemisférico}

El sistema mundial se aleja cada vez más de la bipolaridad ${ }^{2}$ nacida al final de la segunda guerra mundial y se acerca a una multipolaridad en la que participan con mayor intensidad China, Europa Occidental y Ja-

\footnotetext{
1 Arístides Calvani, "La política internacional de Venezuela en el último medio siglo", Venezuela Moderna, Madrid, Editorial Ariel, 1979, p. 491.

Calvani utiliza el concepto de cuenca caribeña cuando se refiere al Caribe y Centroamérica.

Demetrio Boersner también utiliza el término "macrocaribe" para referirse a la misma región. Cfr. vid. Demetrio Boersner, "Venezuela frente a Centroamérica y el Caribe", Perspectiva, Caracas, agosto de 1983.

2 Brown, Seyon, New Forces in World Politics, Washington, The Brookings Institution, 1974, p. 117-18 y 186-90.
} 
pón. ${ }^{3}$ Por razones que no concierne analizar en este trabajo, Estados Unidos ha ido perdiendo poder paulatinamente y ello ha causado la lenta difuminación de la bipolaridad y el surgimiento de nuevas potencias. El primer sintoma grave de la debilidad norteamericana fue el fracaso de la guerra de Vietnam y posteriormente las crisis en Nicaragua, Irán y Afganistán la comprobaron.

Al ascender Ronald Reagan a la presidencia de los Estados Unidos se endurecieron las relaciones de este país con la Unión Soviética, la política exterior norteamericana se tornó más agresiva y creció el armamentismo; todo ello con el objeto de que los Estados Unidos recuperaran el terreno perdido.

A nivel hemisférico, el panorama de las relaciones interamericanas se caracteriza por el debilitamiento de la hegemonía que Estados Unidos ostentaba totalmente, a raíz de la revolución cubana. De igual manera, sobresale el surgimiento de nuevos actores en el área, entre ellos Brasil, México, Venezuela y Cuba, país este último que constituye la principal amenaza al poderio norteamericano por sus particulares relaciones con la Unión Soviética. Junto a estos nuevos actores habría que considerar el papel cada vez más preponderante que desempeñan la socialdemocracia y la Democracia Cristiana internacionales, así como el surgimiento de conjuntos de países, como el grupo Contadora, interesados en ampliar su influencia en Centroamérica, en parte como resultado de la debilidad estadunidense y también en la búsqueda de una participación más efectiva en la región de México y Venezuela. ${ }^{4}$ En el ámbito centroamericano y del Caribe varios acontecimientos debilitaron la posición de los Estados Unidos. En los inicios de la administración Carter se concebía a Centroamérica como una de las áreas más seguras para los intereses estratégicos y económicos norteamericanos, pero la caída de la dictadura de Somoza en Nicaragua, el fracaso del gobierno militar de Romero en El Salvador y los nuevos tratados sobre el canal de Panamá, introdujeron muchos elementos de inseguridad e inestabilidad desde la perspectiva norteamericana.' Aunado a esto, Estados Unidos empezó a perder influencia en el Caribe anglófono con el surgimiento de regímenes políticos en Guyana, Jamaica, Granada, Dominica y Santa Lucía que se autodenominaban "socialistas" y cultivaban estrechas relaciones con Cuba. ${ }^{6}$

Este autor no está de acuerdo con el uso de "multipolaridad" y prefiere el de "poliarquía", haciendo resaltar el papel de las transnacionales, grupos subnacionales, comunidades y del propio Estado-nación en el sistema emergente de la bipolaridad, nosotros utilizamos el primer concepto para hablar del sistema actual en las relaciones internacionales.

3 Vid, "Striking out on their own", Newsweek, Nueva York, 2 de junio de 1980 y Sullivan Scott, "Europe's Mideast More", Time, Nueva York, 2 de junio de 1980.

Los acontecimientos de Irán lo pusieron de manifiesto y también la invasión soviética a Afganistán. Ni Europa Occidental, ni Japón estuvieron dispuestos a embarcarse con los Estados Unidos en su boicot a Irán. Ni siquiera la Gran Bretaña logró que el parlamento aprobara las sanciones económicas a pesar del respaldo de la Sra. Thatcher al gobierno de Carter. La reunión D’Estaing-Brezhnev en Polonia probó la fragmentación del bloque occidental.

4 Luis Maira, "Fracaso y reacomodo de la política de Estados Unidos hacia Centroamérica", Foro Internacional, México, abril-junio de 1980, p. 721.

s Ibidem, p. 696.

- Fitzroy Nation, "Trinidad un nuevo factor en el Caribe", El Diario de Caracas, Caracas, 23 de abril de 1980.

Anthony Maignot, "Cuba y las naciones del Caribe", El Diario de Caracas, Caracas, 24 de abril de 1980. 
Así, la política originalmente planeada por Washington para América Central, que consistia en lo fundamental en apoyar la transición gradual de las dictaduras a regímenes democráticos "resguardados o viables", sufrió serios reveses. ${ }^{7}$ Con el triunfo de los republicanos (1981) y en vista de la pérdida de poder que Estados Unidos sufría en el ámbito internacional, se inició un periodo caracterizado por el endurecimiento de la política exterior dirigida por Reagan. En este contexto se inscriben los intentos de desestabilización del régimen revolucionario nicaragüense, el creciente apoyo logístico y económico a los regímenes contrarrevolucionarios de El Salvador y la invasión a Granada de octubre de 1983. En lo referente a América Central la política republicana se ha movido dentro de un esquema globalizante de origen estratégico que ubica los sucesos de la región en el escenario de la confrontación esteoeste, asumiendo una actitud defensiva ante los supuestos avances soviéticos. ${ }^{8}$ En este sentido, habria que añadir, no obstante, que hay un elemento común en la política exterior de las administraciones de Carter y Reagan y es su incapacidad para entender las reformas que muchos paises de América Latina exigen, ligando su política exterior a la de los sectores sociales más conservadores y atribuyendo las insurrecciones populares que persiguen cambios a la "influencia comunista" de Cuba.

El atraso y las contradicciones sociales imperantes en el área caribeña y centroamericana han desencadenado revoluciones populares. En algunos casos han sido encabezados por grupos marxistas, de distintas tendencias, que pretenden solucionar los problemas de sus respectivos países mediante la instauración del socialismo. Esta situación ha sido benéfica para Cuba, cuyo interés nacional es, en buena parte, la difusión de su modelo socialista y la búsqueda de aliados, justificado teóricamente con el "Internacionalismo proletario". 9 También para Venezuela la región caribeña forma parte de su interés nacional, puesto que el mar Caribe baña la mayor parte de sus costas y parece no estar dispuesta a que aumente la influencia de Cuba.

México es otro país vinculado a la región por su situación geográfica y por los lazos históricos y económicos que lo unen con ella. A partir del gobierno de Díaz Ordaz nació el interés por cultivar mejores relaciones con los países centroamericanos con el objeto de obtener mercados para las manufacturas mexicanas y beneficiarse con el surgimiento del Mercado Común Centroamericano. ${ }^{10} \mathrm{~A}$ partir del régimen de Luis

James Nelson Goodsel, "El Caribe: una nueva serpiente en el paraíso", El Diario de Caracas, Caracas, 3 de mayo de 1980. La derrota electoral de Manley en Jamaica acabó su acercamiento a Cuba.

7 Maira, op. cit., p. 699.

8 Luis Maira, "La política de Reagan y la crisis de Centroamérica", Centroamérica en crisis, San José, EDUCA, 1982, p. 366.

- Silviu Brucan, La disolución del poder, México, Siglo XXI Editores, 1974, p. 140.

Decimos esto porque Cuba necesita ampliar el número de países independientes de Estados Unidos a su alrededor para sobrevivir y romper con el cerco que le ha sido impuesto a través de la OEA desde 1964. Brucan considera que "el internacionalismo proletario representa realmente la extensión de los intereses nacionales por el escenario mundial".

10 The Europa Year Book, 1976, A World Survey, vol. II, Londres, Europa Pubiications Limited, 1976, p. 1057. Comercio Exterior, México, 6 de marzo de 1980, vol. 30 núm. 3, p. 302. En 1979, por ejemplo, las exportaciones hacia Centroamérica sumaron ciento treinta y seis millones catorce mil dólares y ocuparon el cuarto lugar en orden de importancia después de Estados Unidos, Alemania y Japón. Centroamérica constituye un importante mercado para los productos manufacturados mexicanos tales como automotores, electrodomésticos, etcétera. 
Echeverría se inició una politica más independiente y durante el régimen de López Portillo se consolidó; en gran parte gracias a que México se convirtío en un gran exportador de petróleo en 1979, su participación en la zona se tornó más destacada. Al igual que a Venezuela, a México, preocupado por la radicalización que puedan alcanzar los gobiernos de sus vecinos del sur, le interesa participar en la política de la región y evitar la consolidación de gobiernos extremistas que, más adelante, puedan influir en su política interna.

Durante los últimos años, Venezuela ha tenido un papel cada vez más importante en el Caribe, por eso ha buscado el apoyo de México para suministrar petróleo a esa zona, tratando de encontrar un aliado en su política. A principios de agosto de 1980 se firmó el acuerdo de ayuda mexicano-venezolano según el cual ambos países se comprometieron a suministrar a Centroamérica y el Caribe hasta 16000 barriles diarios de petróleo a precios más bajos que los del mercado mundial y extendiendo créditos a largo plazo. ${ }^{11}$ Con leves modificaciones y una suspensión temporal del suministro venezolano a Nicaragua, se ha mantenido la esencia del pacto de San José hasta el presente. ${ }^{12}$ No obstante, deben tenerse en cuenta las diferencias entre la política exterior mexicana y la venezolana. Las buenas relaciones de México y Cuba contrastan con las de Venezuela hacia la isla caribeña. ${ }^{13}$

Si bien ni al gobierno de México, ni al de Venezuela conviene el fortalecimiento del socialismo, cabe recordar el corte liberal de la politica exterior mexicana signada por sus particulares relaciones con los Estados Unidos, que se ha manifestado en el no reconocimiento del gobierno franquista en España, en la negativa de acatar el bloqueo a Cuba decretado por la OEA, en la ruptura de relaciones con Chile en 1973 $y$, posteriormente, cuando se rompieron relaciones dıplomáticas con Somoza. Esta última jugada, llevada a cabo cuando ya se preveía el fracaso de Somoza, le hizo ganar prestigio internacional y le ayudó a consolidar su amistad con los revolucionarios nicaragüenses. ${ }^{14}$

Hasta 1982, fecha en la que coinciden el giro de la diplomacia venezolana por causa de la guerra de las Malvinas y el entibiamiento de la política exterior mexicana debido a la crisis económica, hubo divergencias importantes en las políticas de ambos paises. La cancilleria venezolana dio pleno respaldo a José Napoléon Duarte en El Salvador, en tanto que la mexicana llegó a declarar que las relaciones con este país eran difíciles a raiz del asesinato de un periodista mexicano..$^{15}$ Más aún, en agosto de 1981 los gobiernos de México y Francia emitieron una declaración conjunta en la cual reconocieron a la oposición guerrillera salvadoreña como una fuerza política representativa, ${ }^{16}$ en tanto que Venezuela, junto con otros países latinoamericanos, se declaró en su contra, acusándola de ser una interferencia en la política interna de El gracias a las presiones de Venezuela, Costa Rica y México denunció la

1 El Diario de Caracas, Caracas, 1 de abril de 1980.

12 Facts on File, Nueva York, 17 de julio de 1983, p. 601.

13 En 1979 Fidel Castro visitó México.

"Castro in Mexico", Newsweek, Nueva York, 29 de abril de 1979.

El Diario de Caracas, Caracas, 12 de julio de 1980.

En 1981 López Portillo declaró que Cuba era el pais latinoamericano más querido para

México, Facts on File, Nueva York, 23 de febrero de 1981, p. 135.

is Facts on File, Nueva York, 20 de mayo de 1978, p. 409.

is Proceso, México, núm. 192, 11 de agosto de 1980.

16 Facts on File, Nueva York, 28 de agosto de 1981, p. 638. 
Salvador. ${ }^{17}$ Algo similar ocurrió con Nicaragua: mientras que la cancillería mexicana dio pleno respaldo a la Junta de Reconstrucción Nacional, el gobierno de Herrera Campins se mostró más cauto e insistió constantemente en la necesidad de mantener el pluralismo democrático en Nicaragua.

A nivel hemisférico tambien se observa el creciente interés de Francia e Inglaterra en el Caribe. En los primeros años de gobierno de Luis Herrera, tanto Francia como Inglaterra buscaron a Venezuela como un aliado a sus intereses coloniales y neocoloniales. ${ }^{18}$ La política exterior del presidente venezolano coincidió en aquel momento con Europa que veía a Cuba como su principal enemigo en la cuenca Caribeña, pero, a partir de la crisis de las Malvinas, Venezuela abandonó su acercamiento a las viejas potencias y buscó el fortalecimiento de su alianza con los países latinoamericanos.

\section{Venezuela como actor emergente en América Latina}

Algunos autores, como Charles Ameringer, consideran que el surgimiento de Venezuela como actor importante en la escena internacional se remonta a 1958 , con la democratización de la vida política. ${ }^{19}$ Nosotros no estamos de acuerdo con esta idea; sin negar la importancia de la democracia, nos inclinamos a señalar otros factores, como la consolidación del Estado nacional, la modernización del país y la riqueza que trajo aparejada la renta petrolera, como las causas del fortalecimiento general de la política venezolana.

El petróleo es el centro alrededor del cual gira la sociedad venezolana, su economía y su política exterior. Simón Alberto Consalvi, canciller venezolanao entre 1977 y 1978, afirma: “... En Venezuela es imposible diferenciar política internacional y petróleo". ${ }^{20}$ Es cierto que en el periodo anterior a 1958 el papel de Venezuela no era muy relevante en América, pero ello se debió a que durante esos años el país centró su atención en la modernización. ${ }^{21}$ Recordemos que a principios de siglo, Venezuela era uno de los países más atrasados del continente, pero la importancia del petróleo en el mercado mundial fue un destacado factor de cambio político, económico y social. Ya para 1928 Venezuela era

Facts on File, Nueva York, 2 de septiembre de 1981, p. 638.

Guatemala, Argentina, Bolivia, Colombia, República Dominicana y Paraguay firmaron en declaración conjunta en este sentido y recibieron el respaldo de Brasil, Costa Rica, Ecuador y Perú.

18 Carlos A. Mutto, "París y Caracas una política común hacia el Caribe y Centroamérica”, El Diario de Caracas, Caracas, 15 de abril de 1980.

19 Charles Ameringer, "The Foreign policy of Venezuela Democracy", Venezuela The Democratic Experience, tomado de Simón Alberto Consalvi, La política internacional de Venezuela (1974-1979), Caracas, Editorial Arte, 1980, p. 190. "Durante este siglo y antes de 1959, Venezuela desempeñó un papel pasivo en los asuntos internacionales. Demostraba poco interés y sus presidentes y -dictadores - eran exageradamente obsequiosos con las potencias foráneas, especialmente con los Estados Unidos (...) Esta situación cambió bajo los gobiernos democráticos. Después de 1959 Venezuela se tornó activa, hatsta agresiva en asuntos externos."

Ramón Rivero, La OPEP y las Nacionalizaciones: La Renta Absoluta, Caracas, Fondo Editorial Salvador de la Plaza, 1979, p. 22-3. Algunas de las generalizaciones hechas por Ameringer son bastante discutibles. Por ejemplo, fue durante el periodo de Medina Angarita cuando se creó el impuesto sobre la renta y los ingresos petroleros de Venezuela quedaron en el 50:50 atribuido al gobierno de AD en 1946.

" Consalvi, op. cit., p. 198.

"Cuando hablamos de modernización nos referimos a industrialización. 
el primer país exportador de petróleo y el ingreso del crudo aportaba el $22.6 \%$ del presupuesto; esta proporción fue creciendo, en 1943 al $41.7 \%$ $y$ en 1965 al $73 \% .{ }^{22}$

El ingreso petrolero, toda vez que la propiedad del subsuelo siempre estuvo en manos del Estado, ha sido usado para promover la industrialización. Desde la década de los cuarenta surgieron industrias autóctonas como la de la construcción y otras que han tenido un papel muy importante en las transformaciones del país. Durante la primera mitad del siglo XX Venezuela pierde su perfil agrícola y se convierte en potencia petrolera. Este cambio en la estructura económica, por supuesto, trajo aparejados cambios sociales y politicos. Los terratenientes y la oligarquía tradicionales cedieron su lugar privilegiado al Estado y a la naciente burguesía. Los regímenes dictatoriales fueron sustituidos por la democracia en 1958, después de un accidentado y largo proceso de lucha política.

A partir de 1958 Venezuela empezó a tener mayor importancia internacional porque con la consolidación de la democracia se dio el último paso en la modernización del país. Pero es precisamente a partir de 1974 cuando el abrupto crecimiento del ingreso petrolero, que pasó de 4700 millones de dólares en 1973 a 10500 millones de dólares al siguiente año, le dio a Venezuela "una dramática oportunidad para tomar su propio camino en las relaciones internacionales". ${ }^{23}$ En América Latina este fenómeno se ha manifestado de diversas maneras en los últimos años: desde préstamos a Centroamérica y el Caribe, apoyo político a Panamá en sus demandas sobre el canal, hasta posiblemente ayuda militar a Nicaragua y El Salvador. ${ }^{24}$

\section{El interés nacional de Venezuela en Centroamérica}

Una herramienta útil para el análisis de las relaciones exteriores es el interés nacional. No obstante que hay especialistas que por variadas razones no reconocen su validez, nosotros consideramos que nos puede ayudar a comprender la política exterior de Venezuela. ${ }^{25}$

Intentaremos definir el interés nacional de Venezuela, teniendo en

22 Angel J. Márquez, El imperialismo petrolero y la revolución venezolana. Las ganancias extraordinarias y la soberania nacional, Caracas, Editorial Ruptura, 1977, p. 71 y 149.

${ }^{23}$ Robert D. Bond, "Venezuelan Foreign Policy Toward Latin America", Contemporary Venezuela and its Role in International Affairs, Nueva York, New York University Press, 1977, p. 227-28.

${ }^{4}$ Vid. Daisy Argotte, “Mañana viaja Luis Herrera a Costa Rica”, El Diario de Caracas, Caracas, 15 de junio de 1980.

La ayuda a Nicaragua es difícil de probar aunque como veremos más adelante hay evidencias que parecen comprobarlo.

2s Marcel Merle, Sociología de las Relaciones Internacionales, Madrid, Alianza Editorial, 1973, p. 150-154.

Este autor no le da importancia al interés nacional y por ello no lo incluye en el modelo sistémico que elabora para el estudio de las relaciones internacionales. P. A. Reynolds, Introducción al Estudio de las Relaciones Internacionales, Madrid, Editorial Tecnos, 1977, p. $49-59$.

Reynolds hace algunas correcciones al concepto de interés nacional.

Brucan, op. cit. En cambio Brucan en su modelo marxista cibernético si lo utiliza.

James N. Roseneau, The Scientific Study of Foreign Politics, Nueva York, The Free Press, 1971, p. 249. A este respecto Roseneau opina que el concepto de interés nacional no puede ser abandonado porque la declinación de la nación como unidad es un proceso muy lento que puede llevar muchos años. 
cuenta que no puede desligarse su política interior de la exterior. Como ya se ha dicho, el elemento alrededor del cual gira la política, la economía y la sociedad venezolana es el petróleo. Por ello uno de sus intereses vitales es mantener $y$, de ser posible, aumentar el ingreso petrolero. De ahi que su participación en la OPEP sea el objetivo fundamental de su política exterior. ${ }^{26}$ Otro, tan importante como el primero, es su independencia respecto a las potencias y particularmente a Estados Unidos. El relativamente poco peso de Venezuela frente a las superpotencias hace que para obtener una mayor independencia busque la unión con otras naciones del Tercer Mundo que luchan por la conservación de su autonomía y por un trato más justo. ${ }^{27}$ Asi, su política exterior ha sido tradicionalmente anticolonialista y ha defendido la soberanía de los recursos naturales. ${ }^{28}$ El factor ideológico se manifiesta en la política exterior de Venezuela mediante la defensa de la democracia, aunque como veremos más adelante, el contenido que se le ha dado ha variado de un gobierno a otro.

La proyección de los intereses venezolanos en el exterior se ve seriamente limitada por la falta de definición total de sus fronteras terrestres y marítimas. Cabe recordar a este respecto que Venezuela tiene problemas limitrofes importantes con Colombia y con Guyana. Por otro lado, y sin pretender entrar en el análisis geopolítico, la escasez de población en la región sur y el abandono en el que se encuentra resta "poder nacional" a las relaciones exteriores, entendiendo por poder nacional a la suma de factores geopolíticos y nacionales que hacen posible que una nación pueda provectar su interés nacional en sus relaciones con otros países.

El Estado ha propiciado la acumulación de capital en manos privadas y la industrialización a través del gasto público y de una política arancelaria favorable, fortaleciendo a la incipiente burguesía que aparecía ya a comienzos de siglo. La iniciativa privada maneja la producción manufacturera, agrícola, el comercio y el transporte y el Estado se ha reservado la propiedad de las industrias básicas: petróleo, siderurgia y la mayor parte de la electricidad. ${ }^{29}$ Se trata pues de una sociedad capitalista en la cual el Estado tiene una función importantísima, tanto por ser el principal empresario como por ser el promotor de la burguesía nacional por medio de su política económica.

En el caso venezolano el Estado es el que determina el interés nacional en última instancia, gracias a su calidad de propietario del recurso petrolero y de las industrias más importantes. Así, el papel que la burguesía desempeña en la determinación del interés nacional es limitado, pero esto no significa que sus intereses sean ajenos a los del Estado. Es más, durante algunos regímenes han sido impulsados ciertos sectores

26 Consalvi, op. cit., p. 191.

27 La unión con los países del llamado Tercer Mundo puede ser efímera porque el alto ingreso de los países petroleros los coloca en una categoria distinta.

Bond, op. cit., p. 245. Este autor señala que una de las razones de los empréstitos a Centroamérica fueron las críticas surgidas por parte del Tercer Mundo por los altos precios petroleros.

El Diario de Caracas, Caracas, 13 de junio de 1980. El gobierno cubano criticó a Venezuela acusándola directamente de "miserable explotación y del hambre de los paises subdesarrollados no petroleros".

28 Tanto Consalvi, como Calvani en sus respectivas obras coinciden en señalar esto, pero llama la atención el lenguaje usado por cada uno.

Calvani, op. cit., p. 40 y Consalvi, op. cit., p. 11.

29 Bond, op. cit., p. 233-34. 
de la burguesía debido a la coincidencia entre los planes de desarrollo económico estatales y los de alguna fracción de la burguesia. El empresariado nacional, generalmente aliado al capital extranjero y por ello de una gran productividad, reclama su entrada al Pacto Andino, a la ALALC (o ALADI) y recientemente a Centroamérica y el Caribe. ${ }^{30} \mathrm{La}$ acelerada industrialización del país hace que el Estado busque la expansión hacia los mercados foráneos, a pesar de que los suyos no han sido totalmente explotados. Asi, en agosto de 1980, le fue otorgado un préstamo de 4300000 bolívares a Nicaragua con el fin de que adquiriera productos venezolanos "no tradicionales" según el Instituto de Comercio Exterior. ${ }^{31}$ Pero no sólo se buscan mercados para las manufacturas, sino para la compra de petróleo a cambio de inversiones agrícolas y pecuarias. Así Venezuela podría adquirir estos artículos a precios preferenciales. ${ }^{32}$ Todo esto explica la creciente participación de Venezuela en el panorama hemisférico, pero particularmente en el Caribe y Centroamérica. ${ }^{33}$

En conclusión podemos decir que el interés nacional de Venezuela hacia la cuenca del Caribe, de la cual Centroamérica forma parte, radica en que dicha región se convierta en mercado para sus productos, asi como evitar que continúe bajo el dominio total de Estados Unidos. Pero además Venezuela, como país capitalista, está interesada en el mantenimiento y difusión de su modelo político-económico y, por lo tanto, teme la expansión del socialismo en el área, lo cual explicaría su apoyo a Duarte en El Salvador, su negativa a reconocer beligerancia a los rebeldes, sus cautas relaciones con el gobierno sandinista y sus enfrentamientos con Cuba.

\section{Antecedentes históricos de Nicaragua y El Salvador}

A mérica Central ha sido polo de atracción para las potencias mundiales desde el siglo XVII. Su conformación istmica de la que derivan las posibilidades para la construcción de un canal interoceánico, aunada a los intereses comerciales por explotar algunas de las materias primas que la región produce, explican la presencia inglesa desde el periodo colonial español. ${ }^{34}$ Después de la independencia del Reino de Guatemala (1821) y del fraccionamiento de su territorio en cinco repúblicas (1838), los norteamericanos fueron suplantando los intereses británicos, sobre todo a partir de la segunda mitad del siglo XIX. La "fiebre del oro" en

${ }^{30}$ John D. Martz, "Venezuelan Foreign Policy toward Latin America", Contemporary Venezuela and its Role in International Affairs, Nueva York, New York University Press, 1977, p. 190-91.

Este autor no le da el nombre de burguesia sino "elite".

"El Diario de Caracas, Caracas, 9 de agosto de 1980.

32 Argotte, op. cit.

3 Calvani, op. cit., p. 491 . Afirma que Venezuela toma conciencia de su ubicación caribeña muy recientemente. "La política del Caribe - nos dice-impulsada particularmente desde 1969 trata de rectificar los errores del pasado y de vincular nuestro país a los países bañados por el mismo mar que embellece y da vida a las costas venezolanas. Se promueve una intensa politica de cooperación y acercamiento con todos los pueblos de la zona." Nosotros creemos que es exagerado afirmar que antes no estuvo interesada en el Caribe, lo que pasaba es que tenía demasiados problemas internos para preocuparse por otros paises.

${ }^{34}$ F. D. Parker, The Central American Republics, Londres, Oxford University Press, 1964, p. 62. 
Estados Unidos provocó la búsqueda de una comunicación interocéánica en Nicaragua que permitiera un acceso más fácil al oeste de aquel país. ${ }^{35}$ Sin embargo fue a principios del presente siglo cuando Estados Unidos penetró definitivamente en el área con la independencia de $\mathrm{Pa}$ namá, propiciada por ellos, y con la concesión para construir el canal. ${ }^{36}$ A partir de 1909 los norteamericanos se preocuparon por conservar su hegemonía, defendiendo el canal de Panamá y buscando la estabilidad de la región mediante el apoyo a los regímenes más conservadores. ${ }^{37} \mathrm{De}$ 1912 a 1925 los marines norteamericanos ocuparon Nicaragua y lograron la firma del tratado Bryan-Chamorro (1916) que permitia la construcción de un canal a través de Nicaragua y el establecimiento de bases militares, pero dicho proyecto no prosperó. ${ }^{38}$ Nicaragua fue ocupada nuevamente por Estados Unidos de 1928 a 1933 a raíz del levantamiento popular encabezado por Sandino. ${ }^{39} \mathrm{La}$ presencia norteamericana impidió los intentos unionistas en Centroamérica, asegurando así su pleno dominio sobre la zona. Al salir los marines de Nicaragua en 1933 su influencia estaba plenamente consolidada, y gracias al control del canal de Panamá la hegemonía de Estados Unidos fue total en la región. ${ }^{40}$

En 1936 subió a la presidencia Anastasio Somoza García, quien había sido jefe de la Guardia Nacional y participado en el asesinato de Sandino - nacionalista y profundamente antimperialista - que se había opuesto a la intervención norteamericana. El ascenso de la dinastía Somoza data de ese año y se mantuvo en el poder hasta 1979, cuando el hijo, Anastasio Somoza Debayle, fue expulsado del poder por el triunfo del Frente Sandinista de Liberación Nacional. Los Somoza contaron con el firme apoyo de la diplomacia norteamericana; así, salvo breves interregnos, se mantuvieron en el poder 43 años. Durante este periodo de "paz" impuesta se diversificó la economía de Nicaragua gracias a las exportaciones de café, algodón, ganado, caña de azúcar y plátanos; ${ }^{41}$ se abrieron las puertas al capital extranjero y se creó una legislación con el fin de atraerlo;42 se establecieron manufacturas de telas, cemento, ropa, calzado, procesadoras de alimentos, algunas compañías mineras que explotaban oro, plata y zinc y una pequeña refineria. ${ }^{43}$

${ }^{35}$ El norteamericano Vanderbilt construyó una linea de vapores y diligencias para unir los dos mares en Nicaragua. Ralph D. Woodward, Central America a Nation Divided, Londres, Oxford University Press, 1976, p. 138. También el aventurero norteamericano William Walker fue nombrado presidente de Nicaragua con el apoyo de los liberales y pretendió anexar ese país a los Estados Unidos. Ibidem. p. 140-44.

${ }_{36}$ En 1880 Alfred Mahan, padre de la estrategia naval norteamericana, señaló la necesidad de controlar el Caribe y construir un canal en América Central. Mario Rodríguez, Central America, Englewood Cliffs, N. J., Prentice Hall, 1965, p. 109.

"7) Ibidem, p. 116.

38 Ibidem. p. 118 y Parker, ap. cit., p. 226-27.

${ }^{39}$ La presencia militar norteamericana obedeció más a razones geopolíticas, es decir estratégicas y de política exterior, que al respaldo de sus intereses financieros en este pais.

Edelberto Torres Rivas, "El Estado contra la sociedad: Las raíces de la revolución nicaragüense", Estudios Sociales Centroamericanos, San José, vol. 9, núm. 27, septiembrediciembre de 1980 , p. 81 .

${ }_{40}$ Woodward, op. cit., p. 200.

41 John D. Martz, Central America, Chapell Hill, The University of North Carolina Press, 1959, p. 171.

42 Ibidem, p. 168-69.

Los capitales podían entrar y salir libremente y se podía sacar del país tantos dólares como se quisiera.

${ }^{43}$ Parker, op. cit., p. 241. The Europa Year Book, op. cit., p. 1165. 
Durante este siglo XX, El Salvador ha sido gobernado por militares que apoyan al sector agroexportador y a los intereses norteamericanos, como la dinastía Quiñones-Meléndez (1913-34) o los gobiernos dictatoriales que se sucedieron hasta 1948. El cultivo del café se extendió en El Salvador desde la segunda mitad del siglo pasado y trajo la destrucción de las comunidades indígenas y el acaparamiento de tierras en manos de unas cuantas familias. ${ }^{44} \mathrm{La}$ depauperización de los campesinos ocasionada por los despojos los obligó a emigrar hacia la ciudad y hacia Honduras y fue causa de rebeliones populares. En 1932 hubo un importante levantamiento, en el que tuvo gran participación el partido comunista, que fue brutalmente reprimido causando la muerte de entre 30000 y 40000 campesinos, el $4 \%$ de la población total del país. ${ }^{45}$ En 1950 subió Osorio a la presidencia y gracias a la bonanza cafetalera impulsó la economía del país. Con el apoyo técnico y financiero norteamericano confeccionó un plan de desarrollo industrial que incluía la construcción de carreteras, manufacturas, hidroeléctricas, mejoras sanitarias y el fomento del turismo. ${ }^{46}$

Durante la década de los años sesenta los sucesores de Osorio prosiguieron su programa económico. Se establecieron industrias de productos eléctricos, textiles, de cemento, químicas, de ropa y calzado. ${ }^{47} \mathrm{El}$ gobierno apoyó la creación del Mercado Común Centroamericano del cual El Salvador ha sido el principal beneficiario. No obstante, el problema agrario sigue sin resolverse: catorce familias poseen el $95 \%$ de la tierra y no la cultivan intensivamente. ${ }^{48}$ El descontento campesino, las desigualdades y las prácticas antidemocráticas han convertido a El Salvador en campo fértil para la revolución.

\section{La Revolución}

En 1977 inició su ofensiva el Frente Sandinista de Liberación Nacional (FSLN), fundado en 1961 en Nicaragua. ${ }^{49}$ El asesinato de Pedro Joaquín Chamorro, rival político de Somoza, impulsó la lucha incorporando a amplios sectores de la sociedad nicaragüense, incluyendo a la burguesía. ${ }^{50}$ La corrupción de los Somoza, quienes a la sombra del poder lograron crear una fortuna calculada en 500 millones de dólares, hizo posible que los propios empresarios se pusieran en su contra. Los Somoza prácticamente dominaban la economía del país. En septiembre de 1978 el FSLN lanzó la ofensiva final y tras diez meses de lucha armada logró echar a los Somoza del poder. El inminente triunfo de los sandinistas obligó a los Estados Unidos a reconocer a la Junta de Gobierno encabezada por tres sandinistas, un empresario y la viuda de Chamorro.

En El Salvador subió al poder Molina en 1972; pretendía llevar a cabo una reforma agraria, pero la oposición de terratenientes y empre-

\footnotetext{
44 Rafael Menjivar, "El Salvador: el eslabón más pequeño", Le Monde Diplomatique en español, México, septiembre de 1979.

45 Ibidem.

${ }^{46}$ Martz, op. cit., p. 87-9.

${ }^{47}$ The Europa Year Boak, op. cit., p. 505.

48 Woodward, op. cit., p. 252.

49 Neale J. Pearson, "Nicaragua en Crisis", Current History, Washington, noviembre de 1979 , p. 79.

so George A. Lawton, "Estados Unidos en Nicaragua”, Le Monde Diplomatique en español, México, enero de 1979.
} 
sarios lo obligaron a renunciar. En 1977, mediante elecciones fraudulentas, asumió la presidencia el general Carlos Humberto Romero y paralizó las reformas. ${ }^{51}$ La profunda inconformidad social y la represión reforzaron la rebelión popular con programas políticos que iban de liberales a socialistas. Desde entonces la Iglesia salvadoreña ha participado activamente en la denuncia de la violación de los derechos humanos y de la represión y ha sido perseguida. ${ }^{52}$ La lucha armada y las presiones norteamericanas provocaron la caída de Romero y en noviembre de 1979 tomó el poder una junta de militares y civiles. Esta, en un principio, prometió el cese de la represión y una reforma agraria, pero el incumplimiento de sus promesas ha ocasionado la renuncia de varios civiles y la prolongación de la guerra civil. Los gobiernos que han sucedido a Romero han contado con el amplio respaldo de Estados Unidos y de Venezuela que durante el gobierno de Herrera Campins propició el fortalecimiento de la Democracia Cristiana en El Salvador. ${ }^{53}$

\section{Las relaciones exteriores de Venezuela con Centroamérica}

Las relaciones de Venezuela en Centroamérica fueron cobrando importancia lentamente a lo largo del presente siglo. Se seguian con atención los acontecimientos de la región; las continuas intervenciones de Estados Unidos en Nicaragua despertaron inquietud en Caracas en $1928 .^{54}$ Sin embargo, el interés en aquellos años era la consolidación del Estado y el control de su territorio y por eso Venezuela no desempeñó un papel muy importante en el hemisferio durante el periodo de Gómez.

Durante los gobiernos de Eleazar López Contreras (1936-1941) y de Isaías Medina Angarita (1941-1945) se intentó fortalecer las relaciones con América Latina a fin de mejorar la imagen del país y promover la exportación de productos agrícolas. En 1937 se unió a Costa Rica y Estados Unidos para actuar como mediadores en el conflicto fronterizo entre Nicaragua y Honduras. ${ }^{55}$ Pero las fricciones entre Costa Rica y Venezuela, ocasionadas por sostener puntos de vista divergentes, hicieron que esta última se retirara de las negociaciones antes de que terminaran, en 1939. En 1945 un levantamiento cívico-militar llevó al poder a Acción Democrática, siendo Rómulo Betancourt uno de los líderes más destacados. En el periodo 1945-1948 durante el cual el país fue gobernado sucesivamente por una junta y el escritor Rómulo Gallegos, empeoraron las relaciones de Venezuela con República Dominicana, especialmente por la animadversión que existía entre Betancourt, y el dictador Trujillo.

Bajo la dictadura de Marcos Pérez Jiménez (1948-1958) se afirmaron las relaciones con los regímenes autoritarios. Se estrecharon los lazos con Somoza y se desatendieron los reclamos fronterizos de Costa Rica ante Nicaragua en la OEA, en parte por las mencionadas fricciones con Costa Rica. El dictador Anastasio Somoza García hizo un viaje a Ve-

sI Menjivar, op. cit.

52 Vid, Persecución de la Iglesia en El Salvador, Publicaciones del Secretariado Social Interdiocesano, s.p.i. El Nacional, Caracas, 24 de marzo de 1980.

${ }_{53}$ El Nacional, Caracas, 31 de marzo de 1980 y 26 de marzo de 1980.

54 Sheldon B. Liss, Diplomacy \& Dependency. Venezuela. The United States and The .4mericas, Salisburry, Documentary Publications, 1978, p. 92.

${ }^{55}$ Ibidem, p. 103. 
nezuela y fue condecorado con la Orden del Libertador. ${ }^{56}$ También se mantuvieron excelentes relaciones con Trujillo, entre otras cosas, por ser enemigo de Betancourt, el principal opositor del régimen pérezjimenista y quien desde el exilio luchaba contra la dictadura.

\section{El periodo democrático 1958-1974}

La presidencia de Rómulo Betancourt, primer gobierno representativo del partido Acción Democrática después de la dictadura, secaracterizó por el intento de promover la democracia entre los países latinoamericanos regidos por dictaduras como Nicaragua, Haití, República Dominicana y Cuba. ${ }^{57}$ El triun fo de la revolución cubana y su afiliación al socialismo, así como la aparición de las guerrillas en Venezuela, trajo cambios en la política exterior y propició la consolidación de la llamada "doctrina Betancourt". La guerrilla venezolana recibió un gran apoyo logístico y económico de Cuba. El movimiento realmente llegó a amenazar al gobierno de Betancourt y ello explica el surgimiento de la "doctrina" que lleva su nombre y los recelos a la expansión del modelo cubano en la cuenca caribeña. Dicha doctrina negaba reconocimiento diplomático a los regímenes definidos en ellas como totalitarios, al tiempo que pregonaba la autodeterminación de los pueblos e insistía en que "no se debería permanecer indiferente ante el destino del sistema democrático" s8 Ello llevó al rompimiento de relaciones diplomáticas con $\mathrm{Cuba}^{59}$ y con otros países dominados por dictaduras. La doctrina Betancourt también fue aplicada por su sucesor Raúl Leoni del partido Acción Democrática durante su mandato (1964-1969). La política exterior de este periodo, que coincide con la guerra fría, sitúa a la revolución cubana en el marco del enfrentamiento este-oeste.

El ascenso de Rafael Caldera del partido socialcristiano Copei a la presidencia y los cambios en el escenario internacional y nacional hicieron que el presidente adoptara el "pluralismo ideológico" como guía de la politica exterior del país. Caldera argumentaba que era necesaria la revisión del concepto de autodeterminación, pues Venezuela no se podia seguir negando a tener relaciones con muchos paises de organjzación política e ideológica distinta, y menos con sus vecinos "vinculados al nuestro por obligante fraternidad". ${ }^{60}$ Durante su administración se restablecieron relaciones con Argentina, Bolivia, Ecuador, Guatemala, Brasil, Panamá, República Dominicana y Perú y se dieron los primeros pasos tendientes al restablecimiento de relaciones con Cuba. Además su política exterior se hizo más independiente de la norteamericana.

Entre 1958 y 1973 se diversificaron y mejoraron las relaciones exteriores de Venezuela y el servicio diplomático, y poco a poco aumentó el ascendiente del país en el hemisferio. En aquellos años habia problemas urgentes que resolver como el temor al expansionismo brasileño $y$ el arreglo de las fronteras terrestres y marítimas, y hacia ellos se volcó la política exterior. Así, Venezuela se circunscribió a lo más indispensable en Centroamérica y el Caribe.

st Ihidem, p. 172.

s7 Calvani, op. cit., p. 467.

s* Ihidem, p. 469-70.

sq Martz. "Venezuelan Foreign Policy...", op. cit., p. 161.

(1) Discurso de toma de posesión, 11 de marzo de 1969, Calvani, op. cit., p. 473-74. 


\section{La Diplomacia de Carlos Andrés Pérez en Centroamérica}

La administración de Pérez (1974-1978), del partido Acción Democrática, se caracterizó por esgrimir los ideales bolivarianos de unidad y solidaridad, pugnar por la eliminación de las restricciones impuestas a los países en vias de desarrollo y por buscar la unidad latinoamericana. Tanto a nivel mundial como hemisférico, se enarbolaban las banderas tercermundistas y se luchó por el Nuevo Orden Económico Internacional. Indudablemente, en este periodo aumentó el peso de la política exterior venezolana, sobre todo en Iberoamérica; el pais continuó con una política más independiente de la norteamericana y se apoyó en alianzas con otros paises subdesarrollados. ${ }^{61}$

Con el fin de poner de manifiesto la independencia de la diplomacia venezolana respecto a la norteamericana y dar visos populistas a su gobierno, satisfaciendo a la vez a ciertos sectores de la izquierda nacional, Pérez estableció relaciones diplomáticas con Cuba y luchó por que le fueran levantadas las sanciones implantadas por la OEA. En este mismo sentido apoyó la creación del Sistema Económico Latinoamericano, propuesto por México, que intentaba promover el desarrollo de la región, frenando el avance norteamericano. ${ }^{62}$ Asímismo, respaldó las pretensiones de Bolivia de obtener una salida al mar y las de Panamá para que le fuera devuelto el canal. A la vez, la administración de Pérez también fue consecuente con los intereses de la burguesía interesada en el aumento de la presencia venezolana en Centroamérica y el Caribe y en la incorporación de Venezuela al Pacto Andino. ${ }^{63}$

El excedente petrolero fue usado para ampliar la acción en la cuenca caribeña. Así, al tiempo que se utilizaba una parte para financiar proyectos en los países que la componen, se mejoraba la imagen de una Venezuela criticada por los altos precios petroleros y se evitaban los efeclos inflacionarios que hubiera traido la entrada de los petrodólares.

En diciembre de 1974 Pérez se reunió en Ciudad Guayana con los presidentes de Costa Rica, El Salvador, Guatemala, Nicaragua y el jefe del gobierno panameño y se acordó que Venezuela daria ayuda económica a la región mediante la suscripción de la Declaración de Guayana. ${ }^{64}$ Se dispuso una ayuda de 80 millones de dólares para una agencia de ventas de café centroamericana y la creación de la compañía Cafés Suaves Centrales, la cual con un cártel trataría de controlar las fluctuaciones a la baja en los precios del café.

Más adelante, se unieron a esta compañía Ecuador, Venezuela y México. También contribuyó Venezuela con 60 millones de dólares para el Banco Centroamericano de Integración Económica. ${ }^{65}$ Otra forma de ayuda fue el financiamiento a la balanza de pagos por medio de la venta de petróleo. Este se vendió en $50 \%$ menos de su valor internacional a los países centroamericanos y se acordó que el otro $50 \%$ lo podrian colocar en sus bancos centrales respectivos y usarlo para inversión doméstica. Esta especie de préstamo seria pagadero a 25 años y mientras tanto se abonaría a Venezuela el $8 \%$ anual de intereses. ${ }^{66}$

A principios de 1975 el recién creado Fondo de Inversiones de Vene-

"1 Martz, op. cit., p. 156-57.

62 Ibidell, p. 171-73.

n. Bond, op. cit., p. 246.

o4 Calvani, op. cit.. p. 492.

-s Martz, op. cil., p. 174.

th Ibidem, p. 168. 
zuela (FIV) otorgó ayuda a Centroamérica; concretamente a la Compañia Salvadoreña de Café. Además, Venezuela participó en la construcción de una refinería en Costa Rica aportando el petróleo crudo que constituía el $50 \%$ del capital, y también respaldó otros proyectos costarricenses. El FIV prestó 150 millones de dólares aproximadamente para ła construcción de una fábrica de papel y pulpa en Honduras y el resto del capital fue aportado por Argentina y México ${ }^{67}$ En mayo de 1975 se acordó la creación de la Flota Mercante del Caribe en sociedad con México. Posteriormente el Caribe fue incorporado a los acuerdos petroleros contenidos en la Declaración de Guayana.

Desde el punto de vista financiero, los años de mayor actividad fueron 1974-75; posteriormente se redujo el flujo de divisas al exterior porque aumentaron las demandas internas de desarrollo y pasó el boom petrolero. En 1974 se entregaron quinientos cuarenta millones de dólares por medio del Banco Central, al Fondo Monetario Internacional; quinientos millones de dólares al Banco Mundial para la compra de petróleo y una contribución de quinientos millones de dólares al Banco Interamericano de Desarrollo, pagaderos a cinco años. Además aportó ciento cincuenta millones de dólares al Banco de Desarrollo del Caribe, a la Corporación Andina de Desarrollo y al Banco Centroamericano de Desarrollo Económico. ${ }^{68}$

El hecho de que la ayuda financiera a Centroamérica redujera su ritmo no significó que Venezuela disminuyera su importancia en el área, que se manifestó en el apoyo dado a Panamá para lograr la recuperación del canal, lucha que fue vista como un problema latinoamericano. ${ }^{69}$ Asimismo, se opuso a las intenciones guatemaltecas de anexarse Belice, para evitar problemas con sus vecinos caribeños angloparlantes.

En el panorama centroamericano destaca el apoyo dado por el presidente de Venezuela a los sandinistas. Parece contradictorio que después de la ayuda financiera otorgada a la Nicaragua de Somoza, a partir de 1978 se diera apoyo a los sandinistas. Se han elaborado múltiples interpretaciones para explicar este cambio. Se habla de disgustos personales entre Somoza y Pérez, de malversación del dinero entregado por Venezuela a Somoza o de que Pérez intentaba poner en práctica la política de la Internacional Socialista. En aquel momento no faltaron argumentos para justificar este viraje; se dijo que Venezuela por su "vocación democrática" no podia "aceptar situaciones que atenten contra la libertad y dignidad del hombre" y que debía luchar por la defensa de los derechos humanos. ${ }^{70}$

A principios de 1978 Venezuela pide a la OEA que investigue la violación de los derechos humanos en Nicaragua. ${ }^{71} \mathrm{~A}$ partir de ese momento utilizó toda su influencia en dicho organismo para denunciar los continuos crímenes del gobierno de Somoza. ${ }^{72}$ En octubre de 1978 la Comisión Interamericana de Derechos Humanos visitó Nicaragua y

67 Ibidem, p. 179.

68 Pedro Pablo Kucynski. "The Economic Development of Venezuela. A summary view as of 1975-76", Contemporary Venezuela and its Role in International Affairs, Nueva York, New York University Press, 1977, p. 62-3.

${ }^{69}$ Consalvi, op. cit., p. 6.

70) Ibidem, p. 13-14.

1 Facts on File, Nueva York, abril de 1968, p. 883.

72 Consalvi, $o \dot{p}$. cit., Intervención en la reunión de consulta del ministro de Reląciones Exteriores de la OEA en Washington, respecto al caso de Nicaragua, 22 de noviembre de 1978. 
furiosa represión que padecía el pueblo nicaragüense, pero la OEA no sancionó al gobierno de Somoza, sólo mostró "preocupación" por los sucesos. ${ }^{73}$ Curiosamente, al mismo tiempo que Pérez atacaba públicamente a Somoza, mantuvo con él varias reuniones secretas con el fin de encontrar una salida política al conflicto. En julio de 1978 se llevó a cabo una de estas reuniones en la isla de la Orchila y en ella Somoza aceptó llamar a elecciones. Pérez deseaba evitar que se radicalizara el conflicto, pero cuando el dictador nicaragüense faltó al acuerdo, Pérez intensificó su apoyo a los sandinistas. Se afirma que a pesar de la enemistad entre ambos mandatarios se mantuvieron en contacto hasta el final. ${ }^{74}$

En septiembre de 1978 Venezuela ofreció apoyo militar a Costa Rica en caso de que continuaran las violaciones de territorio por parte de la Guardia Nacional nicaragüense. También presionó a la oEA para que actuara como mediador en el conflicto.

Presumiblemente el apoyo a los sandinistas no fue solamente político sino militar, pues en diciembre el gobierno norteamericano pidió que cesara el apoyo de Venezuela, Costa Rica y Panamá a los sandinistas. Es también curioso que cuando Costa Rica capturaba guerrilleros en su territorio éstos eran remitidos a Panamá y Venezuela, quizá para de ahí regresar a Nicaragua. ${ }^{75}$

En 1978 la actitud asumida por Venezuela en el problema nicaragüense contrastaba con la norteamericana. Se veía claramente que Venezuela estaba consciente de la influencia y del poder alcanzados debido a su alianza tácita con Costa Rica y Panamá. Se ha señalado que desde un principio los esfuerzos de Pérez se centraron en evitar la radicalización de la revolución. Así, dio su apoyo a los "terceristas", la fuerza más moderada dentro del Frente Sandinista de Liberación Nacional. ${ }^{76}$ En cambio, la diplomacia norteamericana fue vacilante, en un principio dio todo su apoyo a Somoza, por un momento pensó en retirárselo, pero después dio marcha atrás. Sin embargo, en octubre, ante las presiones del Congreso y la debilidad de Somoza, Carter decidió suspender nuevamente la ayuda y presionó al Fondo Monetario Internacional para que paralizara un préstamo de veinte millones de dólares. ${ }^{77}$

Es posible que las diferencias personales entre Somoza y Pérez, junto con la politica de la Internacional Socialista y las ambiciones de Pérez de convertirse en líder del Tercer Mundo sean las causas del apoyo de Venezuela a los revolucionarios. Desde la reunión de 1976 en Caracas, la Internacional Socialista, a la cual Acción Democrática pertenece, manifestó su intención de luchar contra las dictaduras y en noviembre de 1978, en el Congreso de Vancouver, la Social Democracia acogió y dio respaldo a los sandinistas. ${ }^{78}$

7.3 Facts on File, Nueva York, 17 de noviembre de 1978, p. 1019 y 14 de diciembre de 1978, p. 1018.

${ }^{74}$ El Nacional, Caracas, 8 de febrero de 1979.

75 Facts on File. Nueva York, 11 de diciembre de 1978, p. 618 y 13 de octubre de 1978, p. 823. El Diario de Caracas, Caracas, 31 de mayo de 1979.

${ }^{76}$ Eloy Lanza, El subimperialismo venezolano, Caracas, Fondo Editorial Carlos Aponte, 1980 , p. $138-40$.

7 Facts on File, Nueva York, 1 de febrero de 1978, p. 91, 16 de mayo de 1978, p. 593, 13 de octubre de 1978 , p. 823 y 1 de noviembre de 1978 , p. 823.

78 "Resolución sobre América Latina", Nueva Sociedad, Bogotá, núm. 40, enerofebrero de 1979, p. 217:18. 


\section{Luis Herrera Campins y Centroamérica}

La administración de Luis Herrera Campins (1979-1984), del partido socialcristiano Copei, siguió participando activamente en el Caribe y Centroamérica. ${ }^{79} \mathrm{La}$ cooperación financiera continuó y, como dijimos antes, se firmó un acuerdo con México para proporcionar conjuntamente petróleo a là región. Se otorgaron préstamos a Honduras, Guatemala, Costa Rica, Panamá y El Salvador para el financiamiento de proyectos de desarrollo así como para equilibrar la balanza de pagos. Hasta el 31 de diciembre de 1979 el FIV había prestado 1421282297.56 bolívares (en ese momento el tipo de cambio era de 4.30 Bs. por 1 dólar U.S.). Además se dieron nuevos préstamos al Banco de Desarrollo del Caribe y a la República Dominicana, ${ }^{80}$ si bien, la reducción de los ingresos petroleros registrada a partir de 1982 hizo que disminuyera en importancia su participación económica en la región.

En cuanto a la política de Herrera Campins en Centroamérica habría que distinguir dos periodos. En el primero, de 1979 a los primeros meses de 1982, se observa un cambio notable en la política hacia esta región debido al temor de un posible aumento de la influencia cubana que lo llevó a una convergencia casi total con la política norteamericana. ${ }^{81}$ Desde luego, también influyó en su actitud hacia El Salvador el hecho de que Duarte perteneciera al partido Demócrata Cristiano, tendencia a la cual está afiliado el partido Copei, en el poder en Venezuela. Como resultado de la expansión cubana en el Caribe a la que Venezuela es particularmente sensible por el apoyo que en el pasado dio este país a la guerrilla venezolana, entre 1979 y 1981 las relaciones cubanovenezolanas se deterioraron profundamente llegando a una virtual suspensión. ${ }^{82}$ Así, las fricciones entre ambos paises alcanzaron graves extremos. Primero, Cuba se negó a dar salvoconductos, como exilados políticos, a los cubanos que pidieron asilo en la embajada venezolana de La Habana (primer semestre de 1980, cuando ocurrió el incidente de la embajada peruana); tres meses después la justicia venezolana declaró que no tenía suficientes pruebas para condenar a los anticastristas cubanos y venezolanos aparentemente implicados en 1976 en el sabotaje de un avión cubano en Barbados que ocasionó la muerte de todos los deportistas cubanos que iban a bordo.

A partir de 1982 se inició el segundo periodo en la politica exterior herrerista. Con la guerra de las Malvinas, en la cual la administración Reagan dio pleno respaldo a las exigencias británicas haciendo a un

Jesús Seguías, "CAP Denuncia una alianza para controlar a América Latina", El Diario de Caracas, Caracas, 14 de agosto de 1980.

79 Luis Cova. "Redescubrimiento del Caribe Oriental", El Diario de Caracas, Caracas, 20 de diciembre de 1979.

* Yadira Calderón, "Venezuela hace un fabuloso aporte al Fondo de la OPEP", El Diario de Caracas, Caracas, 15 de junio de 1980.

${ }^{81}$ A este respecto se puede citar el discurso de despedida del embajador William Luers en Venezuela en el cual señaló las similitudes entre las políticas de Washington y Caracas, Número, Caracas, julio 4 de 1982. También un informe del Departamento de Estado norteamericano que habla de Venezuela como un "aliado indispensable" para los Estados Unidos.

El Día, México, 4 de enero de 1981.

*2 El Diario de Caracas, Caracas, 29 de abril de 1980.

El Universal, Caracas, 2 de abril de 1980; El Diario de Caracas, Caracas, 3 de mayo de 1980. 
lado los tratados interamericanos, Venezuela se dio cuenta de que algo similar podría ocurrirle en el caso de sus reclamaciones territoriales pendientes con Guyana sobre El Esequibo. La crisis británico-argentina propició un distanciamiento de los Estados Unidos y una revisión de su política hacia América Latina, pero particularmente hacia la cuenca caribeña. En este contexto Venezuela inicia un acercamiento hacia $\mathrm{Cu}$ ba, y pide su ingreso al grupo de los No Alineados. ${ }^{83}$ Pero a pesar de que contó con el apoyo cubano, las presiones de Guyana impidieron que fuera aceptada, pues sabían los guyaneses que Venezuela intentaba captar el apoyo de este grupo en sus reclamaciones territoriales sobre El Esequibo ${ }^{84}$ Paralelamente, a partir de esa fecha hay un cambio en la cancillería que trata de situar los conflictos centroamericanos fuera del ámbito del enfrentamiento este-oeste. Así, los intentos de buscar una salida pacífica a los conflictos centroamericanos encuentran eco en la cancillería mexicana y surge el Grupo Contadora en enero de 1983, del que también forman parte Colombia y Panamá.

La revolución sandinista seguia su marcha cuando tomó el poder en Venezuela el demócrata-cristiano Luis Herrera Campins. En un principio el gobierno de Herrera mantuvo una actitud expectante ante los acontecimientos nicaragüenses, pero la inminente caida de Somoza lo obligó a actuar. El 11 de junio de 1979 llegó a Nicaragua una comisión que representaba al Pacto Andino, integrada por el canciller venezolano Zambrano Velasco y el ecuatoriano José Ayala. Advirtieron a Somoza sobre la necesidad de dar una solución a la crisis política y confirmaron su respaldo al gobierno de Costa Rica en caso de violaciones de territorio ${ }^{85}$ Ante el inminente triunfo de los revolucionarios, el 17 de ese mismo mes el Pacto Andino dio su respaldo a los sandinistas refiriéndose a ellos como "legítimos combatientes que pretenden establecer una democracia". 86

La actitud asumida por Venezuela y la ruptura de relaciones de México con Somoza aislaron la política norteamericana, de manera que Estados Unidos decidió actuar conjuntamente con el Pacto Andino. ${ }^{87}$ El 4 de julio de 1979 Viron Vaky viajó a Caracas con el fin de coordinar la política de Washington con la de los países andinos. En esos momentos, la cancillería venezolana intentaba ampliar la base de la Junta de Reconstrucción Nacional para evitar que el control quedara en manos exclusivas de los sandinistas. Venezuela presionó para que entrara a la Junta José Esteban González, vicepresidente del partido socialcristiano de Nicaragua y coordinador de la Comisión Permanente de Derechos Humanos. ${ }^{88}$ Más adelante, Tomás Borge declaró en México que Venezuela fue el único país que condicionó su ayuda a Nicaragua, aunque más tarde la cancillería nicaragüense desmintió esta información. $\mathrm{Cu}$ riosamente en los mismos días que Vaky fue a Caracas llegó a esta ciudad José Esteban González.89

El 17 de julio de 1979 renunció Somoza y salió para el exilio tomando el poder la Junta de Reconstrucción Nacional. La filiación izquierdista

${ }^{83}$ Resumen, Caracas, 18 de julio de 1982.

84 El Nacional, Caracas, 10 de octubre de 1982.

${ }^{85}$ Facts on File, Nueva York, 11 de junio de 1979, p. 446.

${ }^{86}$ Facts on File, Nueva York, 17 de junio de 1979, p. 461.

${ }^{87}$ Facts on File, Nueva York, 4 de julio de 1978, p. 503-4.

${ }^{88}$ Roberto Remo, "Nicaragua Revolución y Contra-revolución", Cuadernos del Tercer Mundo, México, diciembre de 1979, p. 42.

89 El Diario de Caracas, Caracas, 8 de octubre de 1979. 
de algunos de sus miembros y la importante ayuda cubana despertaron temores en Venezuela y Estados Unidos; creían que Nicaragua podía pasar a la órbita soviética. ${ }^{90}$ Más adelante los contactos establecidos con Checoslovaquia y la URSS alimentaron nuevamente las sospechas y el gobierno norteamericano retardó la ayuda prometida a los sandinistas. ${ }^{91}$

Venezuela también quería asegurarse de que no se estableciera un gobierno socialista y no fue sino hasta marzo de 1980 cuando se concretó la ayuda venezolana durante el viaje de Herrera a aquel país. A través del nuevo embajador, Yepes Boscán, hombre de toda la confianza de Herrera, se siguieron los pasos de los sandinistas y se estableció amistad con políticos independientes. ${ }^{92}$ Durante su estancia en Nicaragua, Herrera acordó suministrar 12000 barriles diarios de petróleo y se firmaron acuerdos de cooperación en materia de transporte, comunicaciones y desarrollo industrial..$^{93}$

Luis Herrera no perdió la oportunidad de aconsejar a los nicaragüenses señalando que "el pluralismo es la única forma válida para lograr que la revolución nicaragüense se encamine hacia la democracia" y manifestó su confianza en el futuro de Nicaragua "debido a la amplitud que caracteriza a la Junta de Gobierno".94

Al tomar el poder Reagan y endurecerse la política norteamericana, Nicaragua fue vista como un bastión de la penetración cubanosoviética. Washington retiró toda la ayuda económica a Nicaragua, acusándola de armar a las guerrillas salvadoreñas, y volcó todos sus esfuerzos en fortalecer a las fracciones antiguerrilleras en El Salvador. Esto ha conducido a la revolución sandinista a un gran aislamiento. Ahora bien, con el surgimiento del grupo Contadora en el cual Venezuela, Colombia, México y Panamá dialogan con los países centroamericanos para buscar una salida pacífica al conflicto, evitar la presencia militar de otros países en el área y para que los problemas que vive la región sean sacados de la confrontación entre las grandes potencias, la cancillería venezolana optó por una política que reconoce plenamente al gobierno sandinista. ${ }^{95}$

La politica de Venezuela hacia El Salvador fue de total apoyo a la Junta que asumió el poder en octubre de 1979. En parte porque en ella estaban representados prominentes miembros de la Democracia Cristiana y en parte para evitar que la izquierda tomara el poder. Las relaciones entre José Napoleón Duarte, miembro de la Junta salvadoreña, y Caracas fueron múltiples. Duarte fue presidente de la Organización Demócrata Cristiana de América (ODCA) y estuvo 8 años exiliado en Venezuela, desde 1972 hasta $1979 .{ }^{96}$ Las promesas de reforma agraria,

90 Facts on File, Nueva York, 25 de agosto de 1979, p. 689. A penas subió al poder el nuevo gobierno empezaron a llegar maestros y médicos cubanos a Nicaragua. Se acordó la participación de Cuba en la elaboración de la campana de alfabetización, país que ofreció 710 becas para que civiles y militares estudiaran en la isla.

91 El Universal, Caracas, 5 de mayo de 1980. El Diario de Caracas, Caracas, 20 de marzo de 1980.

92 Richard Izarra. "Yepes Boscán y la acción de un superministro", El Diario de Caracas, Caracas, 26 de abril de 1980.

93 El Diario de Caracas, Caracas, 16 de abril de 1980. El Nacional, Caracas, 31 de marzo de 1980.

94 El Diario de Caracas, Caracas, 24 de abril de 1980.

${ }^{95}$ Facts on File, Nueva York, 17 de julio de 1983, p. 535 y 21 de abril de 1983, p. 320.

96 Rafael Antonio Vives, "El Salvador. El Golpe de Estado", Cuadernos del Tercer Mundo, México, diciembre de 1979, p. 59-60.

El Nacional, Caracas, 27 de abril de 1980. 
nacionalización de la banca y del comercio exterior no se concretaron. La violencia creció, pues el gobierno que sucedió a Romero continuó con la represión. Tanto la derecha como la izquierda se radicalizaron y el grupo ORDEN de ultraderecha ha cometido numerosos asesinatos entre los que se cuenta el del arzobispo Romero. ${ }^{97}$ A finales de 1982 se calculaban en 35000 las muertes ocasionadas por la guerra civil. ${ }^{98} \mathrm{La}$ izquierda se ha agrupado en la Coordinadora de Masas que integra a los Bloques Populares Revolucionarios (BPR), las Ligas Populares 28 de febrero (LP), el Frente Acción Popular Unificado (FAPU) y la Unión Democrática Nacionalista (UDN).$^{99}$

La impopularidad interna del gobierno de El Salvador no impidió que recibiera apoyo de Costa Rica, Venezuela y Estados Unidos. Estos últimos otorgaron entre 1981 y 1982 ayuda a la Junta por 333 millones de dólares. ${ }^{100}$ En 1980 Venezuela otorgó una ayuda de veinte millones de dólares para la construcción de la hidroeléctrica del río Lempa. ${ }^{101}$ Tanto Washington como Caracas dieron todo su apoyo a la Junta por temor de que la izquierda pudiera llegar al poder. De acuerdo con las denuncias hechas por la Coordinadora de Masas, las Fuerzas Armadas de Resistencia Nacional, la UDN, el BPR y el Frente Revolucionario, Venezuela no se limitó a la ayuda financiera sino que en algunos momentos dio armas y municiones a la Junta y preparó a un grupo de mercenarios cubanos y venezolanos. ${ }^{102}$ José Vicente Rangel, prominente político venezolano de izquierda, también presentó una denuncia en el mismo sentido el 30 de marzo de $1980 .{ }^{103}$ El gobierno venezolano negó que hubiera prestado ayuda militar a la Junta en reiteradas ocasiones, al mismo tiempo que Páez Pumar, el vicecanciller, declaraba que la venta de armas que hacia una industria privada venezolana no podía ser tomada como intervención. En aquel tiempo tanto el canciller como el presidente negaron que hubieran dado ayuda militar, pero reiteraron su apoyo a la Junta salvadoreña que estaba, según ellos, comprometida en un "proceso de democratización". ${ }^{104}$ Al mismo tiempo, se denunció que los guerrilleros salvadoreños tenían municiones venezolanas y no se aclaró cómo las habían obtenido. ${ }^{105}$

Oficialmente el representante de Venezuela ante la OEA, Hilarión Cardozo, dijo que las insurrecciones de América Central no eran movimientos populares, con el fin de desacreditar el movimiento salvadoreño. El ex canciller Arístides Calvani en su calidad de secretario de la oDCA dio su apoyo tanto a la Junta, como al ascenso de Duarte ${ }^{106}$ Así,

97 Carlos Coello. "El Salvador, un volcán de rencores que quieren apagar con represión", El Diario de Caracas, Caracas, 29 de abril de 1980.

98 The Europa Year Book. A World Survey, vol. II, Londres, Europa Publications Limited, 1983, p. 299-300.

99 El Nacional, Caracas, 17 de marzo de 1980.

100 The Europa Year Book, op. cit,, p. 300.

101 El Nacional, Caracas, 20 de abril de 1980.

102 El Nacional, Caracas, 2 de abril de 1980, 8 de junio de 1980, 29 de marzo de 1980; El Universal, Caracas, 3 de marzo de 1980 y 29 de marzo de 1980.

${ }^{103}$ El Nacional, Caracas, 30 de marzo de 1980.

104 El Diario de Caracas, Caracas, 17 de junio de 1980; El Nacional, Caracas, 9 de junio de 1980. En este comunicado de la Cancilleria se dice: "Venezuela se siente comprometida con los esfuerzos que adelanta el pueblo salvadoreño, cuyos mejores demócratas se esfuerzan por superar complejos y dificiles obstáculos estructurales a fin de lograr una profunda y definitiva estabilidad social fundada en la libertad, la paz y la solidaridad pluralista."

105 El Diario de Caracas, Caracas, 25 de junio de 1980 y 17 de junio de 1980.

${ }_{106}$ El Diario de Caracas, Caracas, 12 de frebrero de 1980. 
el respaldo irrestricto prestado por el gobierno venezolano a la Junta que gobernaba El Salvador motivó duras críticas por parte de la oposición venezolana; algunos políticos incluso acusaron al gobierno de tratar de "copeyanizar" la política exterior. ${ }^{107} \mathrm{El}$ principal partido de oposición en ese momento, Acción Democrática, y los pequeños partidos de izquierda como el Movimiento al Socialismo y el Movimiento de Izquierda Revolucionaria hicieron denuncias públicas a la política de Herrera hacia El Salvador en 1980. ${ }^{108}$

Encontramos pues en este primer periodo una coincidencia entre los intereses norteamericanos y los venezolanos en El Salvador. Tanto los unos como los otros estaban interesados en la "democratización" de ese país y en evitar que diera un giro al socialismo. ${ }^{109}$

Ahora bien, a partir de 1982 el presidente Herrera endureció sus críticas hacia la política de Washington en Centroamérica. ${ }^{110}$ Junto con la crisis de las Malvinas, otro de los factores que también influyó en este cambio fue la derrota de la democracia cristiana y con ella la de Duarte en El Salvador. El 29 de marzo de 1982 fue electo el conservador Alvaro Magaña como presidente provisional de El Salvador y la ultraderecha, totalmente opuesta a las reformas, obtuvo el control de la Asamblea. ${ }^{111}$ Todo ello aunado a la impopularidad de la política exterior hasta entonces sostenida, hicieron que cesara el apoyo abierto de Venezuela hacia el gobierno de El Salvador y se optara por la salida negociada propuesta por el grupo Contadora en 1983.

En perspectiva histórica, es apenas a partir de 1973 cuando la política exterior venezolana se hace notar en el hemisferio. Como es obvio, tuvo en ello una importancia primordial el aumento brusco del ingreso petrolero, recurso que, como propiedad del Estado, ha financiado el desarrollo económico y político del país así como el surgimiento del empresariado nacional. Lógicamente donde se hizo sentir más la influencia venezolana fue en la cuenca caribeña.

Cuando Venezuela comenzó a tener un papel importante en América Latina, no contaba aún con una política exterior consolidada, planeada desde una perspectiva global y capaz de enfrentar coherentemente los problemas regionales de la magnitud del conflicto centroamericano y de la guerra de las Malvinas. Probablemente haya influido en ello la indefinición de límites que el país todavía padece y que hacen que la delimitación fronteriza con Guyana y Colombia capitalicen la atención de la cancillería.

Venezuela tiene intereses concretos y definidos en la cuenca caribeña: en principio es claro que pretende consolidar su influencia política y económica en una zona geográfica a la que está ligada; por otra parte le interesa impedir el aumento de la influencia soviética en el área, ya que ello podría poner en peligro su modelo democrático capitalista y, por último, también aspira a evitar el control absoluto de Estados Unidos en la región.

107 Utilizando las siglas del partido demócrata cristiano venezolano Copei, se señala el excesivo peso del partido en el poder en la política exterior.

${ }^{108}$ El Diario de Caracas, Caracas, 1 de junio de 1980 y 10 de junio de 1980.

109 William G. Bowdler, "Discurso sobre Centroamérica", Nueva York, s.p.i., 8 de abril de 1980.

James Carter, "Discurso del presidente Carter sobre América Central y el Caribe", Washington, s.p.i., 9 de abril de 1980.

110 Concretamente acusó a los Estados Unidos de encubrir actividades paramilitares en Nicaragua: Facts on File, Nueva York, 23 de marzo de 1982, p. 198.

"I' Facts on File, Nueva York, 3 de abril de 1982, p. 314. 
En términos coyunturales, muchos elementos inciden en la definición de la política exterior venezolana. Uno de esos elementos son los. partidos políticos que, aunque no determinantes, sí ejercen cierta influencia, especialmente en lo referente a las organizaciones internacionales con las que están relacionados los dos grandes partidos del pais: Acción Democrática está afiliado a la Internacional Socialista y Copei, a la Democracia Cristiana. Sin embargo, las diferencias entre estos partidos son más conceptuales que prácticas. ${ }^{112}$

Otro factor que influye en la política exterior venezolana es la multiplicidad de actores que participan en el proceso de toma de decisiones en este campo: el ministro de Energía y Minas, el representante ante la OEA, el canciller, el presidente $y$, en algunos casos concretos, los ex cancilleres y los ex presidentes. ${ }^{113}$ Sin embargo, a pesar de la multiplicidad de actores que participan en el proceso de toma de decisiones de la política exterior venezolana, es necesario aclarar que la posición de los presidentes en turno ha sido clave, le han impreso su propio sello.

Por último hay que tomar en cuenta que esta variedad de factores se mueve en un momento histórico concreto con elementos nacionales $\mathrm{e}$ internacionales en relación variable y por ello también incide en la política exterior venezolana. Por lo tanto, la coincidencia entre la doctrina Betancourt y los tres primeros años de la administración de Herrera Campins se explica por las condiciones históricas. Tanto a principios de los años sesenta, como a finales de la década de los setenta se agudizó la lucha entre las dos super potencias. Primero por el caso cubano y después porque las luchas populares reivindicativas surgidas en Nicaragua y El Salvador fueron vistas por Estados Unidos y Venezuela como parte de la confrontación este-oeste. En cambio, los gobiernos de Caldera y Pérez vivieron el periodo de la distensión lo cual les permitió llevar a cabo una política pluralista, más independiente de la norteamericana, que puso mayor énfasis en las alianzas con el Tercer Mundo y, por ende, en el conflicto norte-sur.

Como resultado de la carencia de la línea diplomática sólida y defini$\mathrm{da}$, los acontecimientos continentales han tenido una influencia directa e inmediata en la formulación de la política exterior hacia la cuenca caribeña. En este sentido, se puede decir que Venezuela es mucho más sensible a los cambios que acontecen en América Latina y, particularmente, a los de la cuenca caribeña, que otros paises como Brasil o México que tienen detrás una tradición diplomática más consolidada.

Queda fuera de nuestro análisis un factor muy importante en la politica interior y exterior venezolana: el ejército. Este es un actor de enorme peso, pero tenemos pocos datos sobre él, ya que la joven democracia venezolana todavía lo mantiene como tema "tabú", aun para los científicos sociales. Su papel clave en la política exterior quizás se deba a la importancia que en ella han tenido los aspectos fronterizos.

112 Indudablemente la Democracia Cristiana está más cerca del idealismo, en tanto que la Socialdemocracia lo está del materialismo. Asi, mientras Calvani -Canciller democristiano en el periodo de Caldera - habla, por ejemplo, de "bien común universal", Consalvi - canciller socialdemócrata de la época de Pérez- habla de "nuevo orden económico internacional"; Vid, Calvani, op. cit., p. 441 y 467 y Consalvi, op. cit., p. 9-19.

11.3 Durante el gobierno de Luis Herrera Campins influyeron en la política exterior las posiciones del ex canciller Aristides Calvani, y en el régimen actual ha sido clara la participación del ex presidente Pérez, especialmente por sus conexiones con Edén Pastora. 